\title{
La historieta como relato de un trauma social en América Latina: los casos Historietas por la Identidad (Argentina) y Acto de Guerra (Uruguay)
}

\author{
MHCJ no 7 | Año 2016 \\ Artículo no 8 (80) \\ Páginas 191 a 215 \\ mhjournal.org
}

\author{
Dra. Laura Cristina Fernández| ninaefe@yahoo.com.ar \\ Universidad Nacional de Córdoba
}

\section{Palabras clave}

Historieta latinoamericana; Memoria;

Discurso

\section{Sumario}

1. Introducción. 2. Metodología.3.

Resultados. 4. Discusión. 5. Conclusiones. 6. Bibliografía.

\section{Resumen}

En el presente artículo se parte de la observación sobre las repercusiones que la crisis económica, política y social de Argentina en el año 2001 y luego, en forma más moderada, de Uruguay, tuvieron sobre el imaginario del campo de la historieta de dichos países. De modo más específico, se pretende analizar cómo esas marcas traumáticas de la crisis se revelan en algunas producciones creadas bajo ese lenguaje popular, pues nuestra hipótesis sostiene que, además de las graves consecuencias para el desarrollo de los países, los mencionados fenómenos, paulatinamente, fueron respondidos por estas sociedades con una preocupación por revisar el pasado, tanto el histórico como el reciente. Uno de los aspectos que mayor presencia ha adquirido en los discursos del período posterior a tales quiebres sociales es el concepto de "memoria reciente", dentro del cual nos interesa particularmente la construcción de la imagen sobre las militancias armadas de los años setenta que reflejan algunas historietas contemporáneas. Desde una perspectiva epistemológica de cruce entre la Historia Social del Arte, la Sociología del Arte, los Estudios Culturales y el Análisis Crítico del Discurso, elegimos como objeto de estudio a las historietas, centrándonos en los casos del proyecto Historietas por la Identidad (VV.AA., Argentina: 2012-2015) y en Acto de Guerra (Rodolfo Santullo - Matías Bergara, Uruguay: 2010).

\section{Forma de citar este artículo en las bibliografías}

Laura Cristina Fernández (2016): "La historieta como relato de un trauma social en América Latina: los casos Historietas por la Identidad (Argentina) y Acto de Guerra (Uruguay)", en Miguel Hernández Communication Journal, nº, páginas 191 a 215. Universidad Miguel Hernández, UMH (Elche-Alicante). Recuperado el de de 20_ de: [ink del artículo en mhjournal.org] 


\title{
Comic as a social trauma story in Latin America: Comic for Identity ( Argentina ) cases and Act of War ( Uruguay )
}

\author{
MHCJ no 7 | Año 2016 \\ Artículo no 8 (80) \\ Páginas 191 a 215 \\ mhjournal.org
}

\author{
Dra. Laura Cristina Fernández| ninaefe@yahoo.com.ar \\ Universidad Nacional de Córdoba
}

\section{Keywords}

Latin-American comics; Memory; Discourse

\section{Summary}

1. Introduction. 2. Methodology. 3 Results.

4. Discussion. 5. Conclusion. 6.

Bibliography.

\begin{abstract}
This paper pretends to analyze how the economical, political and social crisis in Argentina in 2001 (and, then, a moderate one in Uruguay) impacted the comic's field of these counties. Specifically, how these traumatic traces of crisis are revealed on some productions of this popular language: we understand that (beyond the serious consequences in these countries development) this phenomenon was replied by the societies with a concern about the historical and/or the recent past. The concept of "recent memory" is one of the most important aspects on this post-crisis period's discourses. We are interested particularly on how the 70's Guerrilla Image is constructed in some of these actual comics. We adopt an heterodox epistemological perspective, which combines elements from the Sociology of Art, the History of Art, The Cultural Studies and the Critical Discourse Analysis, in order to study the cases of Historietas por la Identidad (VV.AA., Argentina: 2012-2015) and Acto de Guerra (Rodolfo Santullo Matías Bergara, Uruguay: 2010).tension, at the same time that spotlight their boundaries and difficulties.
\end{abstract}

\section{How to cite this paper in bibliographies}

Laura Cristina Fernández (2016): "La historieta como relato de un trauma social en América Latina: los casos Historietas por la Identidad (Argentina) y Acto de Guerra (Uruguay)”, en Miguel Hernández Communication Journal, nº7, páginas 191 a 215. Universidad Miguel Hernández, UMH (Elche-Alicante). Recuperado el _ de de 20__ de: [ink del artículo en mhjournal.org] 


\section{Introducción}

Este trabajo se sitúa en el problema de la construcción de la memoria sobre el pasado traumático reciente en discursos de arte popular y masivo. En particular, buscamos analizar los modos en los que se (re)construye el pasado de la militancia política en determinados discursos estéticos (y) políticos creados en sociedades posdictatoriales como la argentina y la uruguaya.

Nos focalizamos en dos casos puntuales: el proyecto Historietas por la Identidad (Argentina) y la novela gráfica Acto de Guerra (Uruguay). Observamos que estas producciones pertenecen a un fenómeno particular de la última década, posterior a la crisis económica, política y social del año 2001: se trata de una serie de discursos que se ocupan de (re)construir un pasado reciente traumático a partir de relatos artísticos, vinculados directamente con las políticas de D.D.H.H.

De la mano de gobiernos que favorecieron la visibilidad sobre estos temas -minimizados en anteriores períodos, mediante las llamadas "políticas del olvido" (Vezzetti, 2007)-, los reclamos sobre los crímenes del estado dictatorial (1976-1983, en Argentina; 1973-1985 en Uruguay) y la necesidad de una revisión sobre ese pasado, no casualmente emergen en contextos de reconstrucción social, política y económica de los mencionados países.

Por otra parte, observamos que existen factores internacionales que influyen en este fenómeno, vinculados al propio campo de la historieta. Se trata de la aparición de obras que reconstruyen pasados traumáticos (históricos o recientes), ya sea desde la narración de ficción histórica, la mirada documentalista o bien desde las variantes que ofrece el relato en primera persona (como autobiografía y/o testimonio). Algunas de estas historietas -como, por ejemplo, Persépolis, de Marjane Satrapi; Palestina en la franja de Gaza (2002) y Notas al pie de Gaza (2010), ambas de Joe Sacco; o Los surcos del Azar, de Paco Roca (2013)- han servido como referentes en diferentes momentos, aunque los campos argentino y uruguayo han desarrollado características particulares mediante la apropiación y reelaboración de tales influencias.

Asimismo, algunas historietas rioplatenses han logrado actualizar, a partir de su propio lenguaje, las tradiciones de los géneros históricos y documentales de otras formas artísticas. En especial durante la última década, en este campo particular, ha surgido un importante número de obras que tratan sobre hechos históricos utilizando diferentes perspectivas ideológicas y estrategias narrativas.

Hemos adelantado que los casos argentino y uruguayo sobre los que gira este trabajo, son abordados como relatos posdictatoriales, es decir, como discursos que poseen marcas de este trauma social particular (la dictadura y sus abusos) y que, a su vez, se presentan como respuestas a dicha herida colectiva ( $\mathrm{y}$, en ocasiones, también personal). En un marco de políticas gubernamentales tendientes a revisar el pasado, con matices y selecciones diferentes, estas historietas son parte de un discurso mayor que busca rescatar aspectos ocultos o invisibilizados en décadas previas. 
En otra ocasión (Fernández, 2015), hemos estudiado la influencia de la llamada "teoría de los dos demonios" en la construcción de la "memoria reciente" durante los años ochenta y parte de los noventas. Brevemente, señalemos cómo tal postura, que planteaba el escenario del período 19761983 como una guerra entre dos potencias radicalizadas equivalentes: una de "ultraderecha" y otra de "ultraizquierda", imposibilitó una revisión no solo del papel de la sociedad civil sino también de la complejidad de las militancias armadas de los años setenta.

Tras la derogación de las leyes de Obediencia Debida y de Punto Final (21 de agosto de 2003) y el impulso de las causas por apropiaciones, crímenes y desapariciones en la forma de juicios a partir de 2005, en Argentina este debate sobre las militancias se actualizó, materializándose, entre otras narrativas estéticas, en un importante grupo de historietas entre las que se incluye en proyecto impulsado desde la agrupación Abuelas de Plaza de Mayo, que analizaremos en las próximas páginas.

\section{Metodología.}

La perspectiva teórica y metodológica que adoptamos articula elementos provenientes de la Historia Social del Arte, de la Sociología del Arte, de los Estudios Culturales y del Análisis Crítico del Discurso Social. De esta manera, se concibe a la historieta como un producto cultural, como un lenguaje y como un sistema social.

La perspectiva histórica social, nos permite considerar el transcurso por el cual este objeto comercial, de la cultura de masas, llega a ser legitimado como objeto artístico a partir de los últimos años sesenta (Fernández, 2012). Esta validación se produce mediante luchas simbólicas dentro del campo intelectual que, finalmente, influyen en las instituciones del campo del arte: este problema es el que abordamos desde la mirada sociológica.

En la teoría de los campos planteada por de Pierre Bourdieu (1995), se concibe al campo del arte, en nuestro caso de la historieta, como un sistema social de luchas por el poder simbólico, donde los habitus o disposiciones y las prácticas se construyen en el tiempo y en situaciones históricas específicas. El capital en juego, entonces, funciona por diferentes creencias que son construidas, impuestas o negociadas entre los agentes y que varían según el sentido que esté jugando un papel hegemónico en ese momento.

Finalmente, entender una historieta como un discurso, implica comprenderla como una producción de sentido en la cual podemos encontrar huellas de las formas y condiciones en que fue conformada. Es decir, que en estas construcciones desde lo social que son los discursos, existen marcas que nos permiten construir, al menos fragmentariamente, los procesos que determinan los modos en que entendemos nuestra realidad, nuestro mundo, las maneras en que lo representamos.

Otro concepto central en este trabajo es posdictadura (Richard, 2007; Longoni , 2007; Longoni y Mestman, 2010), que difiere de la noción de "apertura democrática". El aparato represivo construido tras los golpes institucionales del siglo XX en Argentina y Uruguay marcó a estas 
sociedades con una profundidad que no es posible subsanar solo con la vuelta a la vida electoral. Las dictaduras, entonces, conforman un pasado traumático al cual estas historietas en particular pretenden responder, pues no se trata de un proceso cerrado, ya que algunas estrategias heredadas del período dictatorial persisten en nuestras sociedades, emergen en prácticas o en el imaginario político y social de nuestra vida cotidiana.

En estos casos que analizamos, la idea de memoria colectiva emerge frecuentemente. Al respecto, Schmucler (2006: 8-9) señala que tal concepto supone una manera en que un grupo, sin importar su dimensión, "se reconoce a sí mismo con relación al pasado". El pasado nos interpela, nos dirige sus reclamos, que no se satisfacen fácilmente. Esta (re)construcción, esta memoria de un grupo social, en cada época, convive con otras en una pluralidad. La memoria, sea individual o colectiva, no existe sino en relación con otra y, por ello, Schmucler la entiende como la práctica de una ética.

Cabe subrayar, además, que la construcción de la memoria no solo no es unívoca ni rígida, sino que está atravesada por otras operaciones selectivas, formas de olvido sobre cuyas diferentes manifestaciones trabaja Ricoeur (1999: 59-60), señalando cómo algunas de ellas ayudan a la conformación de la memoria colectiva. El olvido, entonces, no se reduciría a una acción negativa, sino que se plantea como una estrategia selectiva del pasado, pues existe una construcción dinámica de la memoria, una recreación del mismo.

Existen formas de olvido que, ya sea porque permanecen en el inconsciente o por haber quedado fuera de esa memoria construida en consenso, son reversibles o factibles de volverse eventualmente visibles en los discursos que constituyen las memorias. La imaginación y la memoria, entonces, son operaciones que apuntan a una misma función: "hacer presente lo ausente" (Ricoeur, 1999: 25), no obstante difieren en la temporalidad sobre la que actúan. La memoria en nuestro caso se conduce también hacia el pasado reciente. La narración del pasado histórico o reciente nos remite, entonces, a este problema de la representación a partir de la operación selectiva que es la memoria. En ese sentido, Ricoeur apunta sobre este diálogo entre lo imaginario y lo "recordado", planteado desde el presente no obstante proyectado hacia el futuro.

Entendemos que la construcción del pasado reciente, en estos casos mediante los géneros documental o histórico, se elabora a partir de una puesta en valor, hegemónica o no, según el caso, de algunos aspectos de dicho pasado. Estos pueden ser, por ejemplo, la militancia, las luchas campesinas, los hechos "secundarios" o no profundamente investigados por la historia oficial. Sin embargo, tal revisión o relectura del pasado también posee una finalidad orientada al futuro: ya sea a legitimar determinados valores, a visibilizar debates, u objetivos tan materiales como la aparición de un familiar, como en el caso del proyecto de Abuelas de Plaza de Mayo. En tal sentido, estas operaciones nos muestran que el pasado histórico o mejor, su representación mediante imágenes y relatos, es una construcción en suspenso, pues está ligada al problema de la verdad. 
"Lo verdadero", entendemos, es una concepción también relativa, elaborada a partir de la interpretación, ideológica, influida o condicionada por determinados intereses, hegemónicos o "de resistencia", y de determinada selección de huellas, íconos y de testimonios. Esas fuentes y/o documentos, además, presentan nuevamente el debate sobre la verdad. En primer lugar, el ícono y la huella están sujetos a la compleja operación de interpretación que relaciona a la memoria y a la historia. Este vínculo entrama "lo recordado", tanto en la memoria del individuo como en lo establecido como memoria colectiva, es decir, como la illusio de la memoria, con "lo imaginado", es decir, con ese sustento que permite la operación de recrear o reconstruir (reenactment) el pasado.

Un retrato no es una copia, en la medida en que es una interpretación o, mejor dicho, una búsqueda de la verdad mediante la interpretación [...] El retrato y la fotografía, cuando alcanzan su mayor perfección, dependen de la fase de la elaboración imaginativa del recuerdo y, mediante ese proceso, remiten al problema de la fidelidad (Ricoeur, 1999: 82).

Hemos señalado que la memoria no es unívoca ni rígida, sino que es una construcción, en mayor o menor medida marcada por lo emocional o lo traumático, en la que participamos todos los individuos de una sociedad. Al respecto, Vezzetti (2009: 21) recupera de Halbwachs la noción de "memoria social" como una "práctica que no conserva el pasado sino que lo construye a través de sus huellas, ritos y tradiciones, desde marcos proporcionados por el presente". Este autor refiere a la existencia de una "memoria ejemplar", que permite o intenta extraer una enseñanza en la lectura del pasado bajo las necesidades del presente.

En tal sentido, Vezzetti revisa críticamente la instrumentalidad que ha adquirido el pasado en los discursos políticos, ante lo cual desarrolla un análisis centrado en el caso argentino, examinando las formas de construcción de la desaparición y de la militancia. De este trabajo rescatamos dos observaciones: por un lado, que la conmemoración a las víctimas de la última dictadura, ya sean desaparecidos o asesinados, se ha desplazado hacia un homenaje al mártir sacrificial, poniendo énfasis en una mirada más romántica que pragmática, en la cual las acciones armadas de las guerrillas son silenciadas. Longoni (2007) también ha abordado este problema.

Por otra parte, define un transcurso sobre la construcción de la "memoria reciente": desde la concepción polarizada en los últimos años de la dictadura, la ya mencionada "teoría de los dos demonios" durante la primera posdictadura, la emergencia de testimonios e investigaciones críticas desde fines de los años noventa, hasta una construcción de la memoria como forma institucional (Vezzetti, 2009: 81-84). Esta periodización, explicada aquí en forma sucinta, ha sido una referencia para comprender cómo de sitúan estos discursos que abordamos a continuación y qué construcciones del imaginario social las atraviesan. 


\section{Resultados}

\subsection{La búsqueda del propio pasado: Historietas por la Identidad (2012-2015, Argentina)}

A partir del año 2012, la asociación Abuelas de Plaza de Mayo impulsa este proyecto de la mano de algunos hijos de desaparecidos/nietos recuperados y de varios historietistas invitados; a veces, autoconvocados cuando conocieron el proyecto, para realizar historietas sobre algunos casos de bebés apropiados o desaparecidos en la última dictadura. Existían precedentes dentro de la misma agrupación que, desde el vigésimo aniversario del golpe de estado de 1976, emprendió una serie de campañas para encontrar a los nietos desaparecidos entonces. Desde fines de los noventas, se realizaron diversos proyectos que abordaban varios lenguajes artísticos: Teatro X la Identidad, Música X la Identidad, como también proyectos ligados a las artes visuales , como Pintura Colectiva.

Las historietas comenzaron a publicarse en un blog (http://hisxi.blogspot.com.ar), en donde figuran las cuarenta obras y, algunas de ellas, también en la revista Fierro, la bistorieta argentina (2006 al presente). El fin de este proyecto fue promover la búsqueda de Abuelas, alentando a que los hombres y mujeres nacidos durante el período dictatorial y con dudas respecto sobre su identidad se acercaran a la asociación.

Cada uno de estos relatos gráficos ofrece información sobre las características físicas de los padres desaparecidos, pero también de sus gustos, sus costumbres, sus ideas, "quiénes eran", a fines de delinear diferentes vías para la posible "identificación”. Además, todas ellas finalizan con una voz que los busca: sea un hermano, una abuela u otro pariente vivo que "lo espera". El dirigirse en segunda persona al lector (“Te estamos buscando") es una estrategia asidua en estas historietas. Como se señala en la presentación del catálogo de la exposición que se realizara sobre el proyecto, estas historietas "Son retazos de recuerdos, de información, de compromiso ideológico, de posicionamiento político, de incertidumbres, de distancia... Y, sobre todo, de esperanza" (Biblioteca Nacional, 2014: 2).

Oportunamente (Fernández, 2015) hemos dedicado un análisis más detallado sobra la política institucional de la revista Fierro durante su segunda época. A fines de abreviar dicha referencia en este artículo, nos remitiremos a señalar que la inclusión de algunas historietas del proyecto de Abuelas en sus páginas, tiene una fuerte coherencia con el posicionamiento ideológico político de dicha publicación.

Se nueva etapa de esta revista, que comienza en 2006, la encuentra vinculada al diario Página/12, que ya entonces manifestaba su empatía con las medidas del gobierno de Néstor Kirchner (2003 2007). Alrededor de 2008, dentro de la revista se incrementan en forma paulatina algunas marcas de coincidencia ideológica con la política estatal: ya sea visibilizando las conquistas relativas a la política de DD. HH., o referidas a derechos sociales. Se observa en el discurso general de Fierro 
la actualización del relato peronista con elementos vinculados a las nuevas militancias de centroizquierda, especialmente en los editoriales escritos por su director, Juan Sasturain, como también en otros artículos de guionistas y críticos invitados.

Sin embargo, las historietas publicadas en la revista son menos explícitas en esta operación discursiva. Se abordan los temas de la militancia, la desaparición y la tortura pero se apela más a la fuerza de los relatos, en su mayoría de ficción, basados en hechos reales, que a la denuncia; elemento que caracterizaba a la primera época de Fierro (1984 - 1992). La construcción de militante desaparecido, en los relatos de esta segunda época, intenta escapar tanto de la mirada cándida sobre la militancia, como también de la demonización de los personajes y situaciones. En ese marco, los relatos del proyecto Historietas X la Identidad, se ajustan a la línea de la revista: su foco no es la militancia de los padres, si no la aparición de los hijos.

El desplazamiento del lugar común se presenta como una intención recurrente en los relatos de este proyecto, con algunas excepciones. Los creadores van desde artistas reconocidos en el campo local de la historieta como Fernando Calvi, Salvador Sanz, Marcos Vergara, Matías Trillo, Lucas Nine, entre muchos otros; hasta jóvenes que se inician en el oficio. Tampoco hay un criterio de calidad gráfica homogénea: hay trabajos que reflejan un gran dominio del lenguaje, los ritmos y recursos gráficos muy profesionales y otros que están realizados desde criterios más emocionales, con gran sencillez en el dibujo.

En común, estos relatos conservan su referencia directa a lo testimonial, estableciendo más cercanía con la historieta documental que con la propiamente histórica. Por otra parte, en algunos casos la ficción basada en la realidad o en los relatos de los sobrevivientes sirve como respiro a la dureza de lo narrado. Es el caso de la historieta realizada por Federico Reggiani, en el guión, y Ángel Mosquito en el dibujo (fig. 1), con la escena de los niños que imaginan a aquellos primos desaparecidos.

Como adelantábamos, estos relatos naturalmente evitan la perspectiva asociada a la "teoría de los dos demonios" pero también la mayoría evita referir con candidez sobre los padres militantes desaparecidos o asesinados. Muy pocas de estas historietas reivindican explícitamente la decisión por las armas de estos grupos: sí es habitual el relato sobre la vida política y las acciones de los padres, aunque de un modo centrado en la construcción de factores de reconocimiento en los posibles lectores, sin establecer fuertes juicios de valor sobre la "bondad" o no de sus acciones como guerrilleros.

Hemos señalado este objetivo de ofrecer elementos con el cual el/la "buscadx" pueda identificarse o encontrar aspectos comunes con el padre/la madre desaparecida. Ya sea a través de anécdotas sobre hábitos, gustos y características físicas, estas historietas siempre incluyen fotos o dibujos realistas de los desaparecidos o de los hermanos/familiares cercanos. 
Más allá de esta constante, las formas de encarar los relatos difieren bastante en función del autor al cual se le destina cada historia. En algunas se plantea desde el recuerdo infantil de los hermanos o primos que sobrevivieron: es el recurso narrativo que encontramos en la historieta ya mencionada de la dupla Reggiani - Mosquito, que trata el caso Caielli - Aiub (fig. 1); y en la historieta dibujada por Natalia Medrano, que trata el caso Alarcón - Olivera. En otros, se apela a una narración más poética, que toma fragmentos aparentemente disociados para construir una imagen evocativa y, a su vez, informativa para la persona buscada: es el caso de la historieta de Fernando Calvi, que toma el caso Placci - Garófalo (fig. 2), como también utilizan Paula Peltrín (caso Fresneda- Argañaraz), Pablo Iovane y Néstor Martín (caso Rondoletto - Bermejo) y Lucas Nine (caso Deria - Vaccaro), entre otros.

En otro grupo de casos, se parte de la narración sobre el transcurso militante de sus padres, a veces utilizando fotografías y otros documentos de archivo; por ejemplo Eduardo Molinari para el caso Grando - Cornou - (fig. 3), otras veces desde dibujos que son claramente alusivos al aparato represivo, en formas más o menos explícitas en su posicionamiento ideológico, grupo en el cual encontramos numerosos ejemplos, entre los cuales podemos destacar los de Lautaro Fiszman para el caso Metz - Romero y de Matías Trillo para el caso Menna- Lanzilotto (fig. 4).

En lo que respecta a los estilos gráficos, son tan variados como los autores convocados. La mayoría de estas historias muestran un estilo figurativo sintético, de trazo contundente, hechas a pincel, pluma o entintado digital. Otras, utilizan el color como recurso simbólico, a veces con un gran trabajo de paletas, degradados y detalles, como la realizada por el ya mencionado Trillo, o, de manera más tradicional, en un coloreado acuarelado y sutil, como la historieta de Paio Zuloaga sobre el caso Ayastuy- Bugnone (figs. 5 y 6). Estos dos casos mencionados también muestran el recurso de la alegoría de la calavera para referirse al aparato de represión y desaparición de la última dictadura argentina. También, como señalábamos líneas atrás, la fotografía intervenida artísticamente es un recurso en varios trabajos: tanto el mencionado de Molinari, como también el delicado trabajo realizado por Daniela Drukaroff, Malu Sorondo y Nora Burstein, en el cual se retoma el tema de la infancia para abordar la ausencia, en este caso, de una niña desaparecida, que es representada como un dibujo infantil inserto en las fotos familiares (fig. 7).

En Marzo de 2014 se realizó una exposición de estas casi cuarenta historietas en la Biblioteca Nacional, que luego se llevó a diferentes ciudades del país. Así, de alguna manera, el proyecto comenzó a cerrarse. La falta de efectividad comunicacional no parece haber sido el motivo: el tema, por un lado, logró gran visibilidad en los medios a partir de la identificación de varios nietos en los últimos años, quizá el más resonante fue el de Ignacio Guido Montoya Carlotto; y, por otra parte, a través de la agencia de noticias Télam, comenzaron a publicarse algunas historietas relativas al problema de los desaparecidos.

No obstante, más allá de esta dispersión o implícito cierre del proyecto, el balance como campaña de visibilidad de la búsqueda fue positivo. En un marco institucional que favoreció estas políticas de DD. HH. , es significativo el crecimiento de casos de jóvenes que recuperaron su identidad 
biológica durante los años que duró el proyecto: desde 2012, que contaban 106 los nietos recuperados, hasta 2015, con 119.
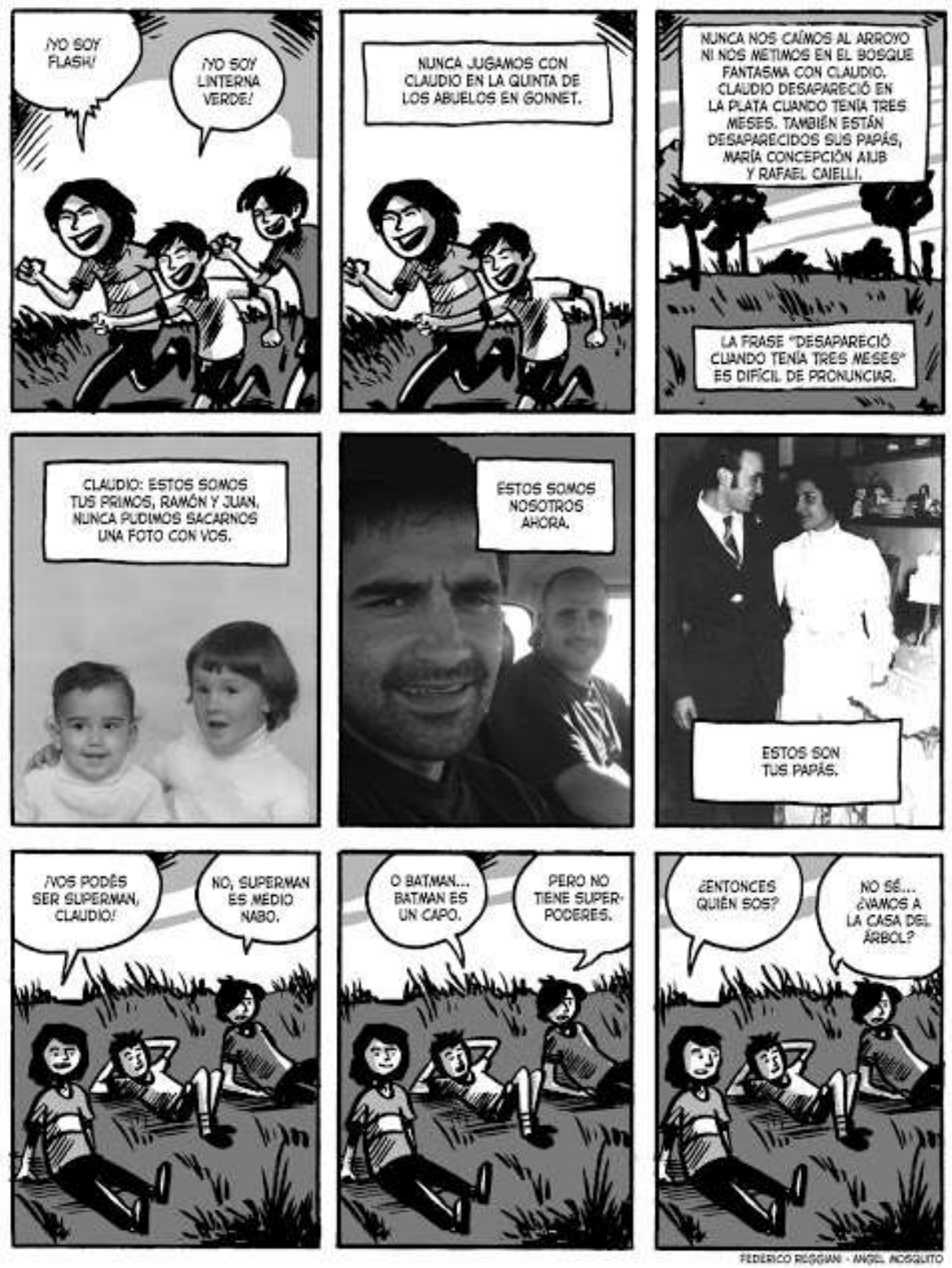

Fig.1: Historieta de Reggiani y de Mosquito. 


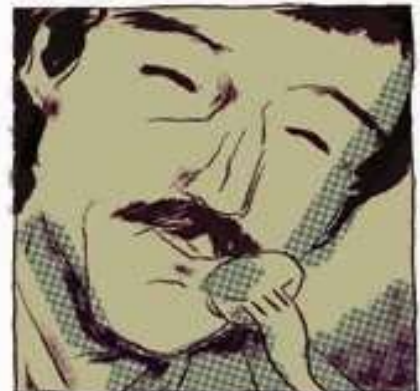

A Eduardo le gusta como cocina su madre, mucho le guste.

El pollo a la portuguesa por ejemplo.

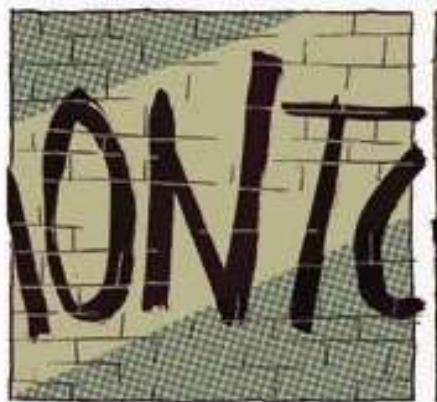

Ambos militaban

É delegado sindical,

ella en la militancia barrial.

Los dos pertenecian

a Montoneros.

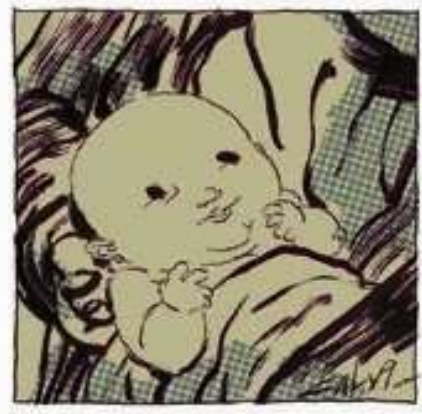

En mayo

de 1976 ,

nace Nicolís.

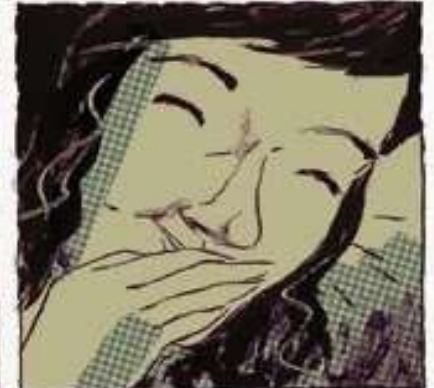

Alba es tímida

cuando rie

se cubre la boca.

Se ruboriza.

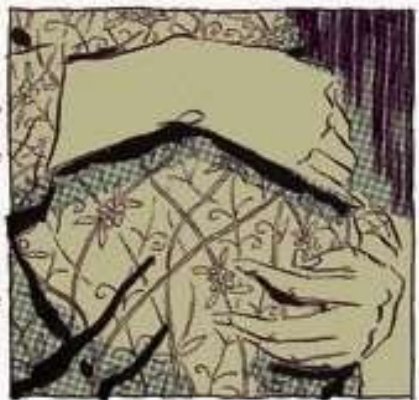

Alba está

muy contenta con sit embarazo.

Le gusta

lucir su panza.

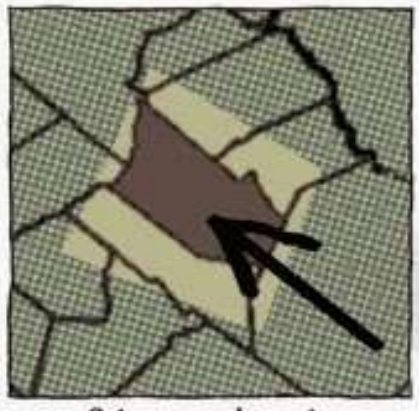

Seis meses después

Alba y Eduardo son secuestrados. Vivian en el Partido de San Martín.

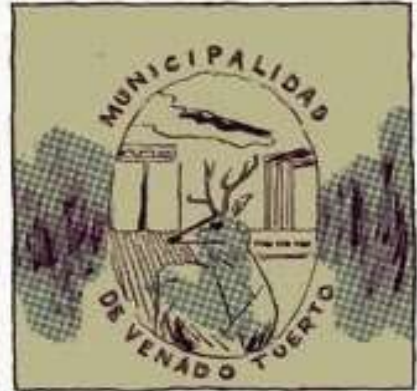

Fue en

Venado Tuerto,

quizís en el 72 ,

que se conocieron.

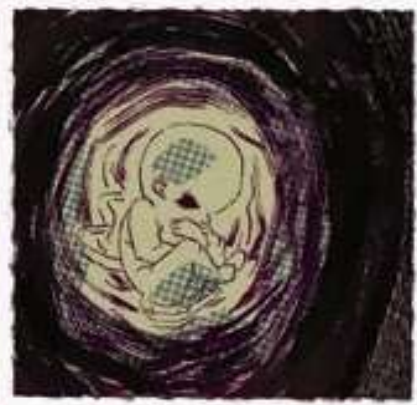

En la panza,

Nicolás.

Por ahora, sus papás,

to llaman: carocito.

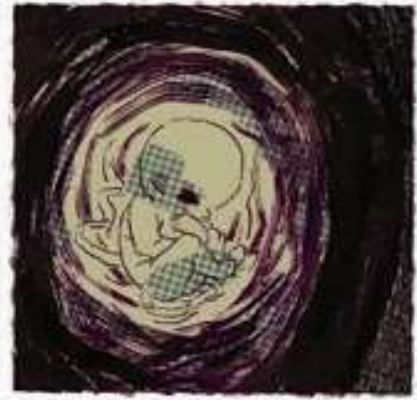

Embarazada estaba Alba cuando se la llevaron. Esperaba su segundo hijjo/a entre mayo y julio de 1977

Fig.2: Historieta de Fernando Calvi. 


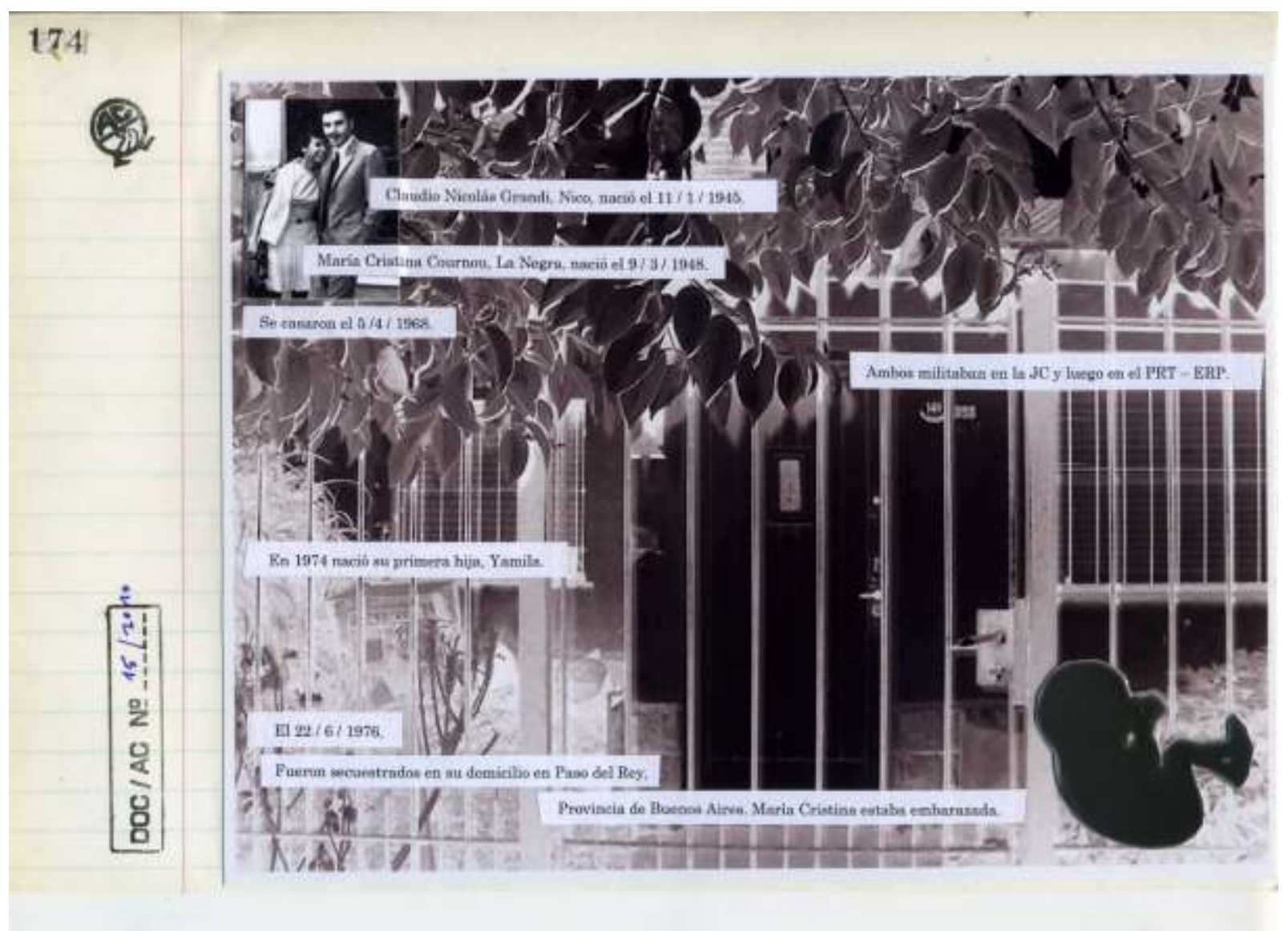

Fig. 3: Historieta de Eduardo Molinari. 

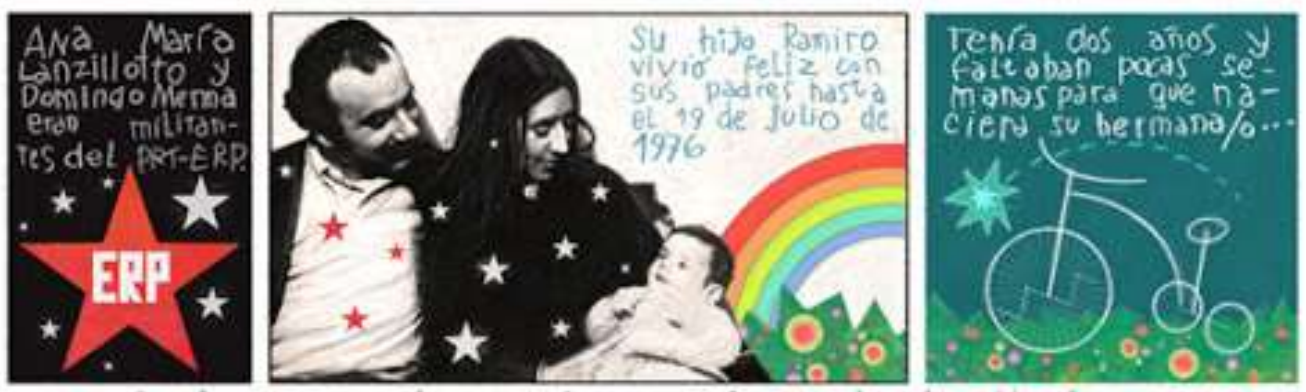

...cuando el macabro aparato reprecivo mont a do por la dictadura hizo desaparecer aso mama, a su papá, al he rmano que esperdba, tamoièn a sos tíos Tina y carlos junto a
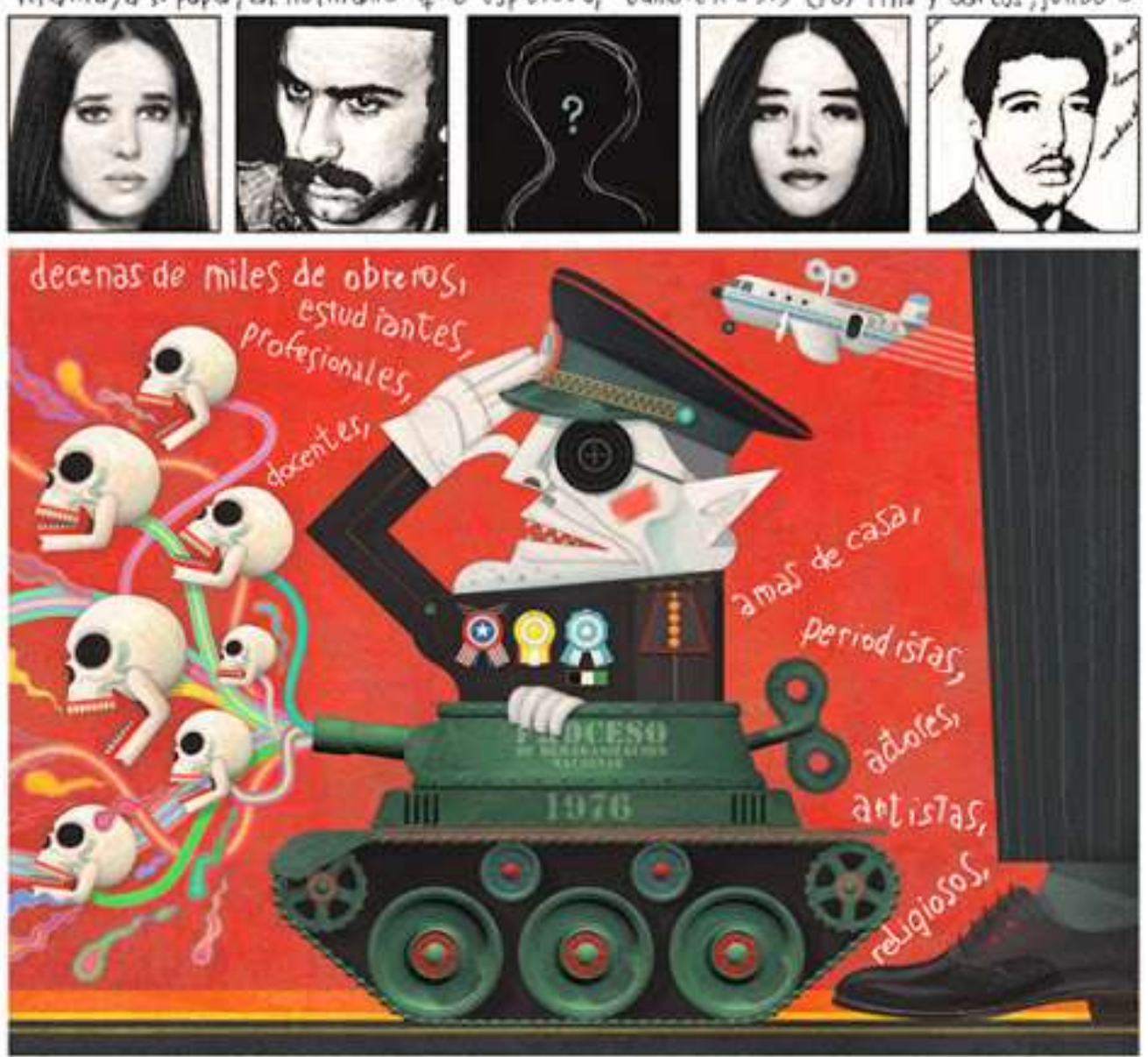

Fig. 4: Trabajo de Matías Trillo. 


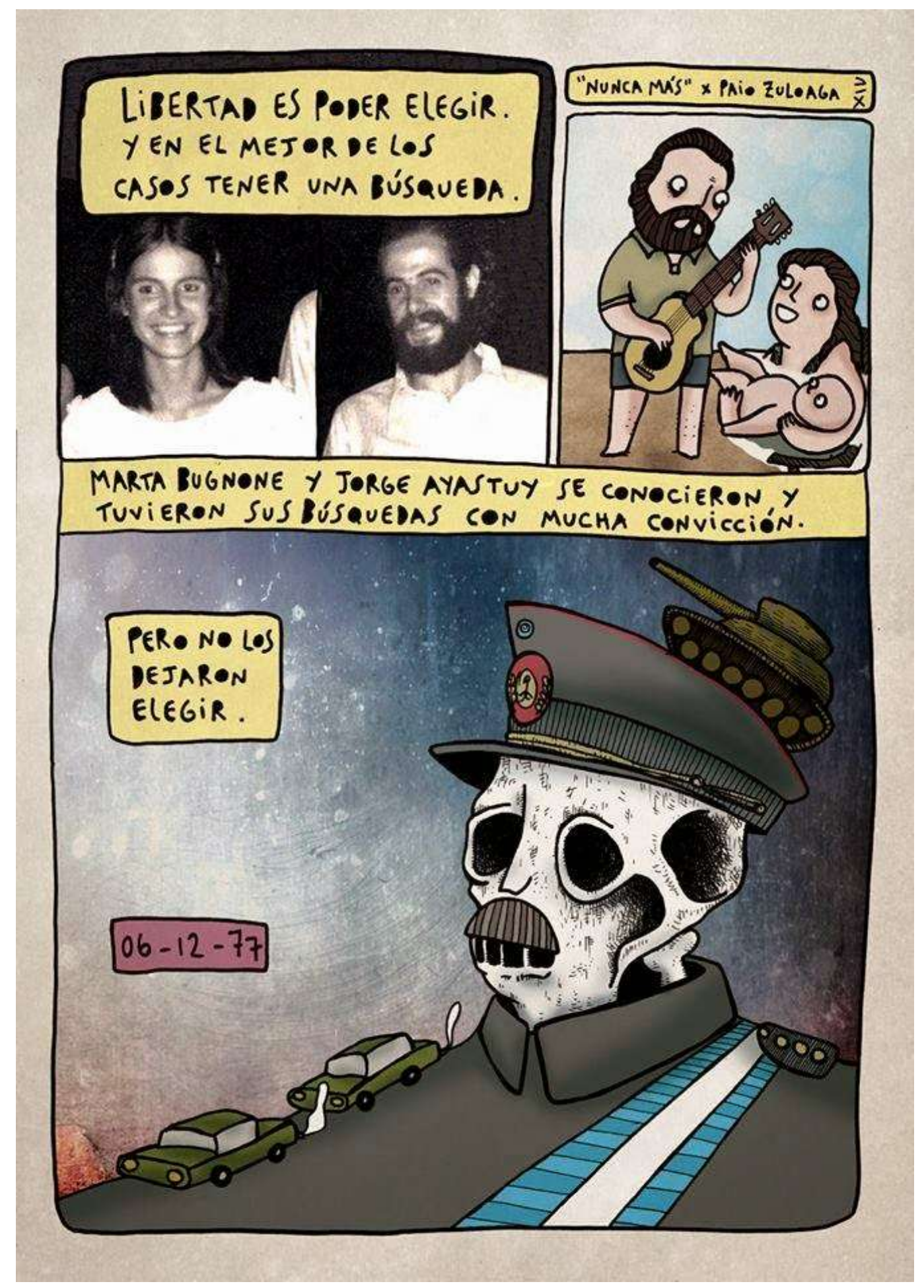




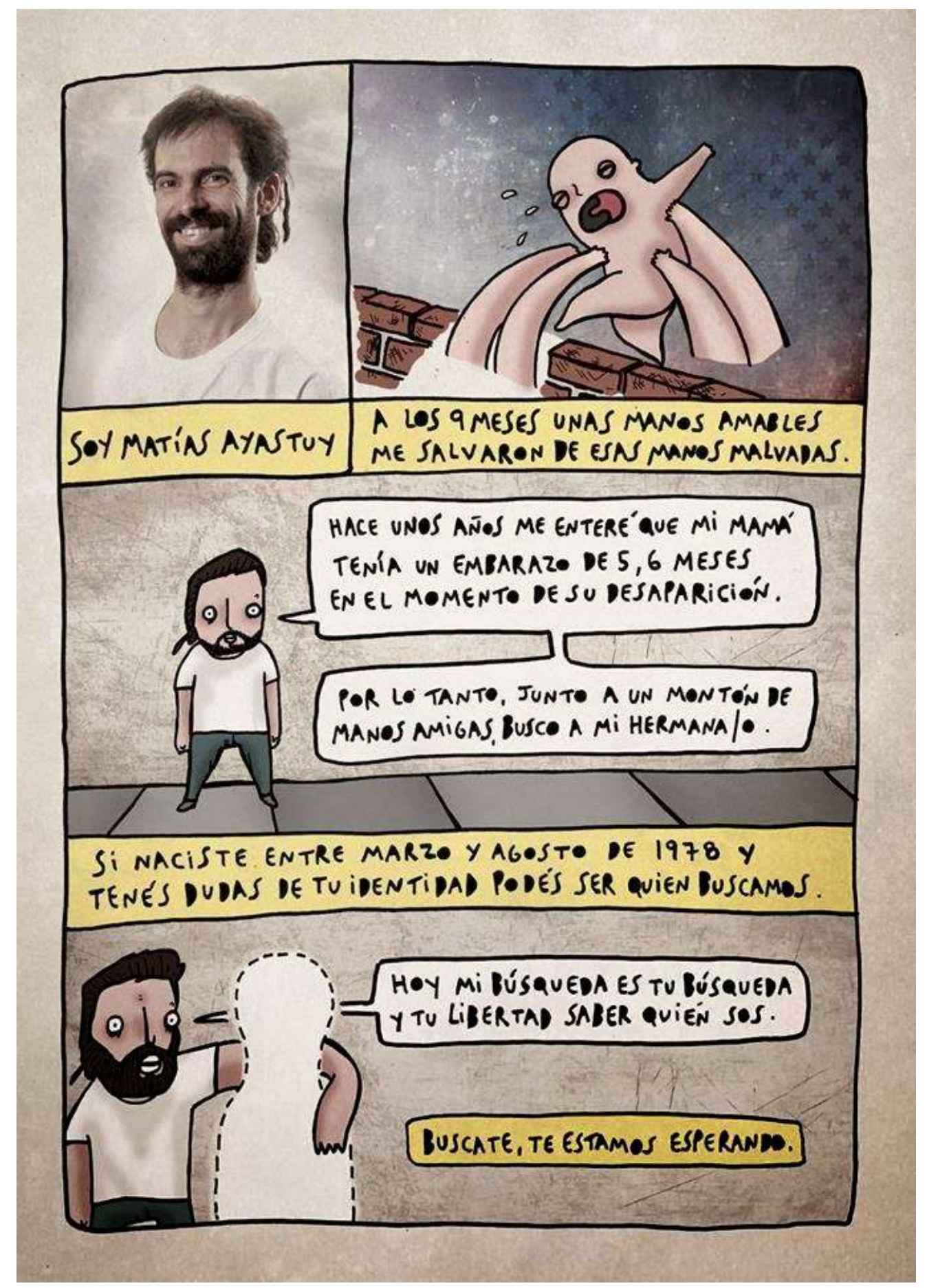

Figs. 5 y 6: Historieta de Paio Zuloaga. 


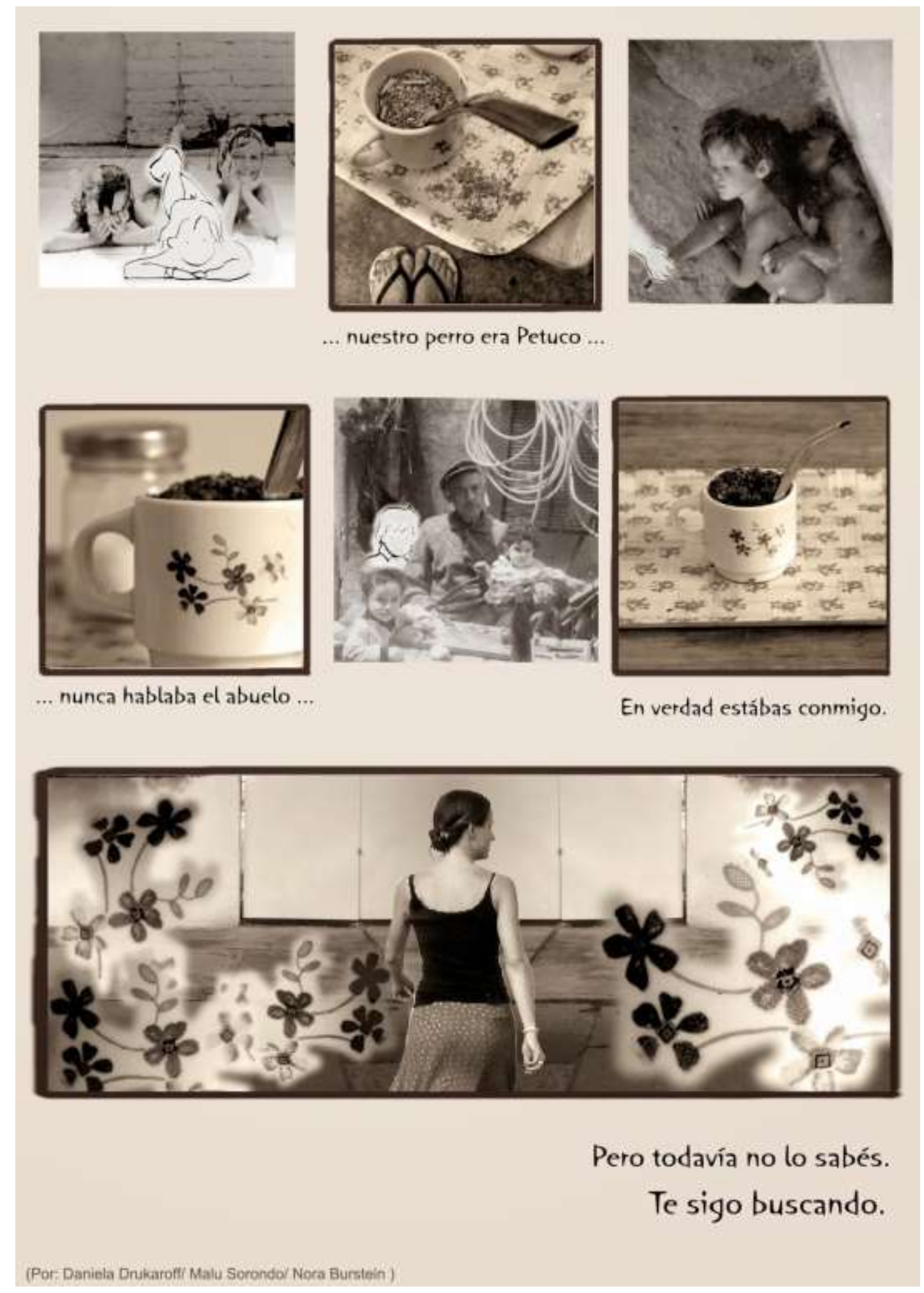

Fig. 7: Historieta de Drukaroff, Sorondo y Burstein.

3.2. La reconstrucción del pasado reciente desde la memoria colectiva. El caso de Acto de Guerra (2010).

Hemos seleccionado la historieta Acto de Guerra (2010), por tratarse de una de las primeras de la escena uruguaya que abordaron el tema de las militancias de los sesenta y setenta y del exilio y, 
además, porque es una producción de dos referentes ineludibles de dicho campo: Rodolfo Santullo, autor del guión y Matías Bergara, autora del dibujo.

A la versión purificada sobre el período dictatorial que se evidenciaba en la "Teoría de los dos demonios", Vezzetti (2009: 99) contrasta otro relato, manifiesto en la segunda etapa de Fierro a la que hemos referido anteriormente: se trata de aquel que busca restituir la dimensión de la militancia y pone en relieve "las metas, las virtudes personales, la abnegación y la entrega, o los estilos de vida (el juvenilismo) mucho más que las prácticas y las acciones". Observa este autor, que la práctica armada queda desplazada de tal reconstrucción "pacificada" sobre el pensamiento militante de los años setenta, que supondría "una militancia que no había tenido otras armas que sus valores personales" (Ibíd. 100).

En el caso anterior, del proyecto Historietas por la Identidad, hemos observado que si bien en algunos casos se explicita la militancia de los desaparecidos, la acción armada es un tema no abordado directamente ni existe una postura valorativa explícita sobre la misma. En cierta forma, responde a esta observación de Vezzetti que citamos arriba: se da una imagen más romántica que pragmática sobre la decisión por las armas de muchos militantes de los setentas.

El caso uruguayo, en este sentido, supone un aporte a los discursos en historietas sobre el pasado reciente, pues juega con los matices en la construcción de personajes y situaciones. Los tupamaros no son caracterizados necesariamente de modo heroico: entre ellos existe algún traidor o "soplón", que no es cruel, sino más bien, inocente o cobarde. Algunos participan de un secuestro (fig. 8) y asesinato de un militar, otros se atrincheran peleando hasta (casi) morir como mártires. Cabe recordar aquí el concepto del "culto al héroe sacrificial" al que refiere Longoni (2007).

Por su parte, la historia escapa también de la mirada simplificadora sobre las fuerzas represivas: si bien son personajes cuyas acciones responden a la lógica de un sistema cruel, no todos ellos están representados de manera desagradable. Por mencionar algunos ejemplos: la dupla Benítez Gutiérrez (fig. 9), dos agentes de inteligencia que bordean el humor grotesco e, incluso, generan alguna simpatía cuando se encuentran en la paradójica situación de tener que rescatar a un tupamaro antes de ser secuestrado. El teniente Arróspide, que demuestra un mentalidad estratégica, o los jóvenes cabos atemorizados que son enviados a asaltar la casa donde se encuentra atrincherado el tupamaro "Nisdec", que es el anagrama de Sendic, quien efectivamente fue uno de los miembros principales del Movimiento por la Liberación Nacional.

El objetivo de esta historieta no es propagandístico, como la búsqueda de familiares desaparecidos es el caso argentino, sino, puntualmente, narrar una "buena historia", como el mismo Santullo nos comentara en una entrevista realizada para la tesis doctoral (Fernández, 2015). Es decir, un relato entretenido, rico en documentación de la época, con personajes complejos e interesantes, que entrama el género ficcional-histórico con el documental y el noire. Esta articulación de géneros es observable en la estructura del libro, que intercala textos de 
testimonios de sobrevivientes a la tortura, en primera persona y a veces extraídos de fuentes documentales secundarias, con las historietas de ficción basada en esos u otros testimonios.

Acto de Guerra posee varias marcas de su contexto de emergencia. Por un lado, fue editada a partir del subsidio de los Fondos Concursables del Ministerio de Educación y Cultura del estado uruguayo, lo que ha supuesto el crecimiento de la producción en ese país durante los últimos diez años. La mayoría de los "relatos gráficos" surgidos con el apoyo de dichos premios pertenecen al género histórico, pues esas producciones están orientadas no solamente al mercado tradicional sino, en particular, a la difusión en las escuelas.

En ese marco, esta historieta constituye un caso excepcional respecto del tipo de relatos hasta entonces editados que abordaban lo histórico. Principalmente, porque esta historieta trabaja sobre el pasado reciente de su país a partir de hechos concretos entre los años 1968, 1972 y 1975. Incluso anécdotas sobre el exilio, algunas de relevancia mediática, como el asilo de la embajada de México a perseguidos políticos en Uruguay, y otras del nivel de lo cotidiano del militante común. A partir de estos fragmentos de memorias, los autores construyen un relato verosímil que abarca diferentes aspectos de la circunstancia política, social y cultural de aquellos años.

Federico Reggiani señala al respecto como uno de los aportes de esta historieta es "evitar el regodeo en la tortura o el confinamiento: no hay puras víctimas, sino militantes que se encuentran, discuten, combaten" (2010). La memoria sobre ese pasado se construye a partir de hechos reales, articulados bajo una premisa ficcional, en forma fragmentaria, desde diferentes puntos de vista: no solo desde los militantes y exiliados, sino también desde policías, militares, traidores. Se trata, como dijimos, de historietas construidas a partir de testimonios y de otros relatos y posibilidades que la ficción ofrece, como bien señala Reggiani (Ibíd.). Se trata, a su vez, de historias reconstruidas mediante el relato oral, las anécdotas familiares y la selección propia de la memoria.

Por otra parte, a diferencia de otros casos de relatos que abordan el pasado reciente, se recurre a una narración muy cuidada en los ritmos y diálogos, dejando que la ideología subyacente, que sin dudas tiene, actúe en un segundo plano. El dibujo de Bergara no persigue el realismo, sino la expresividad, la atmósfera que logra mediante aguadas delicadas articuladas con una tinta suelta, con manchas y trazos contundentes (figs. 8 y 9). Este estilo aporta soltura y sordidez, de manera precisa para ofrecer la fluidez al relato, contrastar y amalgamarse con el sólido guión que ofrece Santullo. 


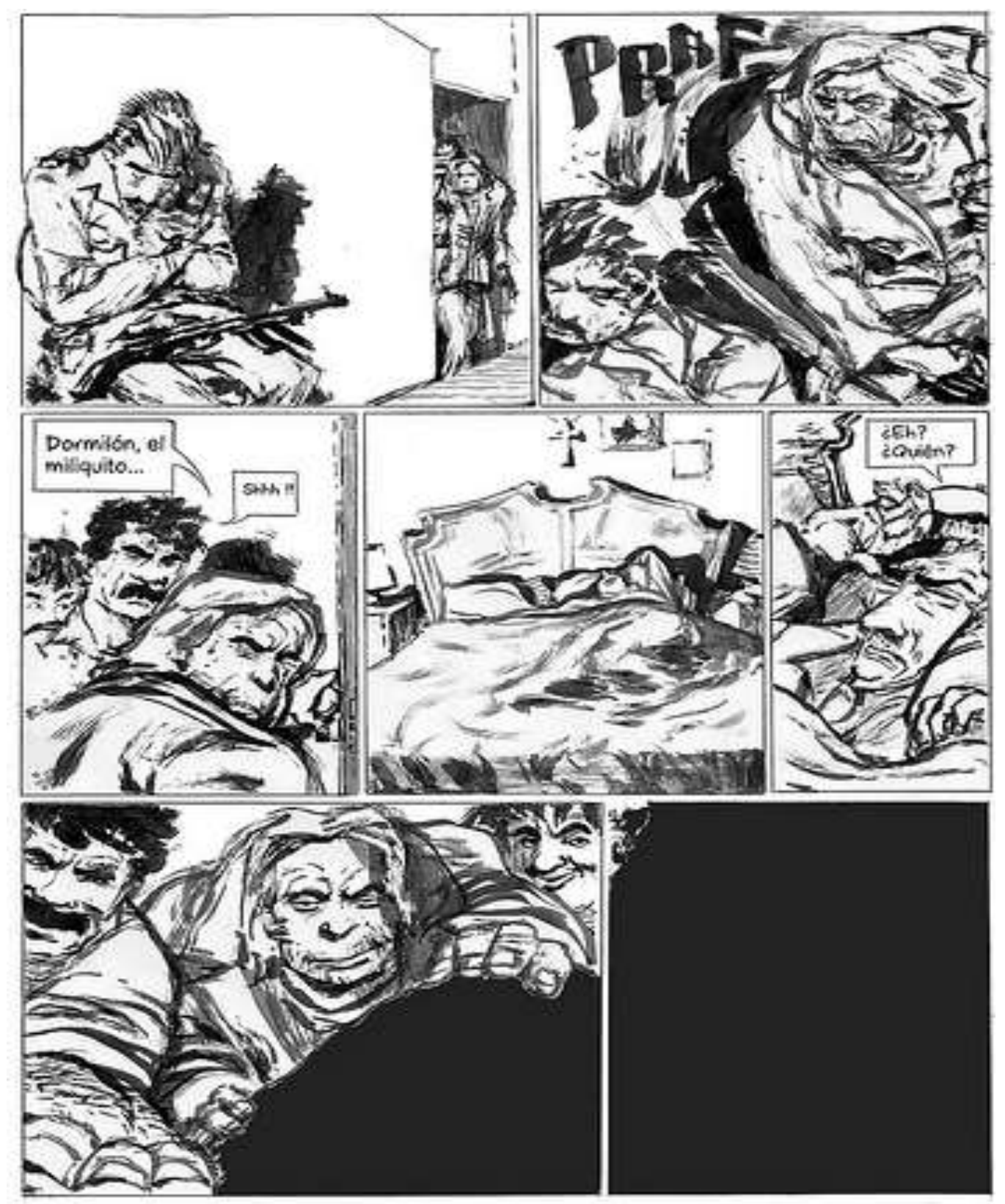

Fig.8: El secuestro a un militar, en Acto de Guerra. 


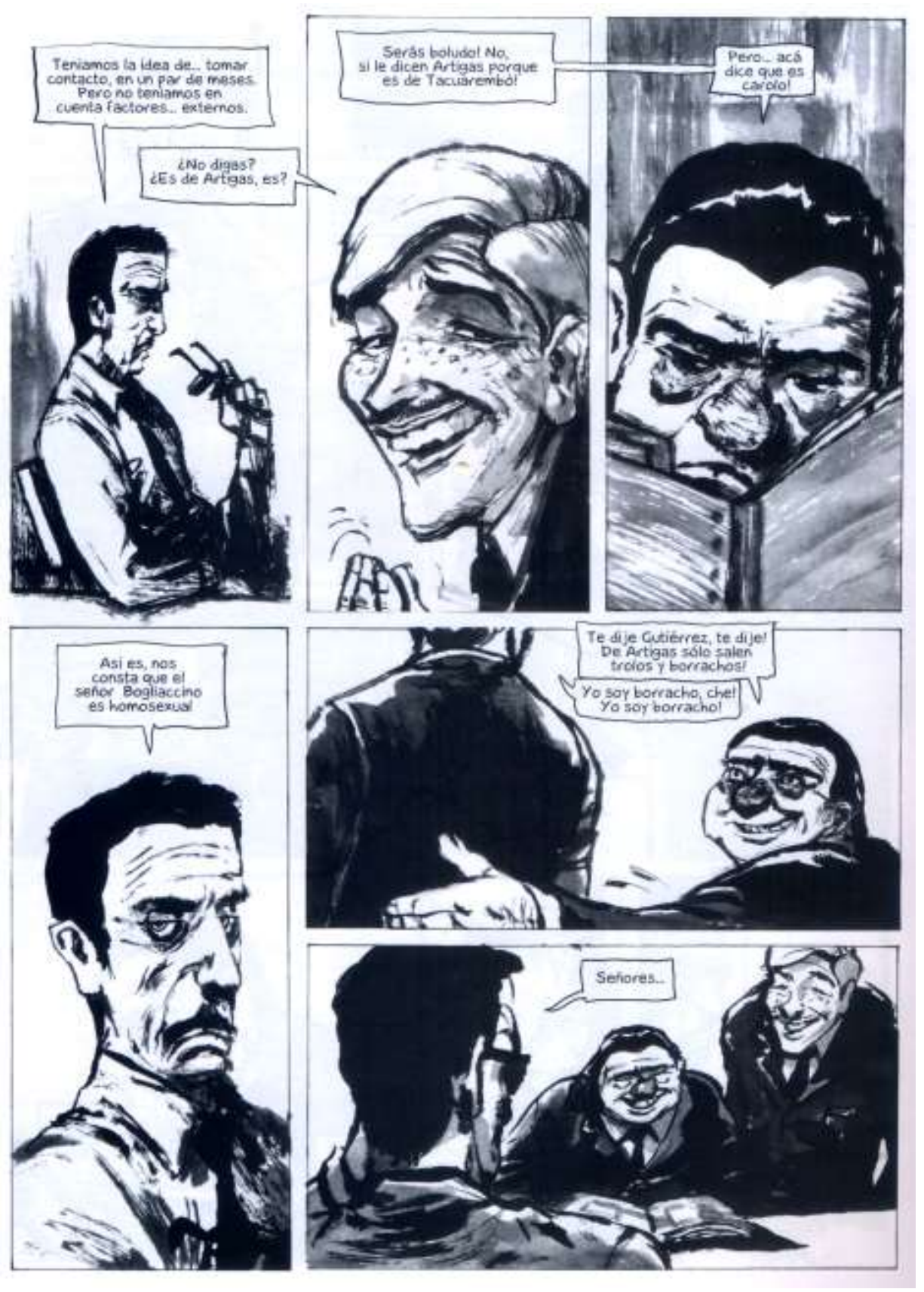

Fig. 9: Algunos "antagonistas" de Acto de Guerra.

\section{Discusión}

Hemos señalado que el debate sobre las militancias armadas de los años setenta como también la dimensión del robo de bebés y los vejámenes sufridos por las víctimas del terrorismo de Estado en algunos casos han sido invisibilizados, en otros minimizados, durante las décadas del ochenta y noventa, tanto en Argentina como en Uruguay.

Fue siempre, por lo tanto, un tema sensible de abordar dentro de los discursos hegemónicos sobre la memoria de la última dictadura. Como mencionamos, o bien se los simplificó bajo la llamada "Teoría de los dos demonios" o bien bajo el falso intento conciliador durante la década 
de los noventas que supusieron las "políticas del olvido" (que, peligrosamente, en la Argentina actual parecen haber cobrado impulso en los discursos oficiales).

Entonces, fue transgresor para muchos ciudadanos, y para otros, quizá entendido como oportunista, que el kirchnerismo se apropiara de esta problemática en su discurso desde el comienzo de su gestión. Más allá de la posible capitalización política, sin duda era una necesidad en la sociedad post-2001, que se supo asumir con un gran sentido de los procesos históricos.

Paulatinamente, la militancia de los setentas comienza a visibilizarse y a problematizarse en diferentes espacios culturales y políticos. Las historietas que hemos tratado aquí, emergen entre los discursos resultantes de dicha agenda, y por ello también cargan con la tensión de ser obras que articulan un discurso político, que puedan ser sospechadas de "panfletarias", estigma con el cual toda obra estético-política tiene o ha debido lidiar. A ello suma, la complejidad que aún persiste en el debate público, sobre las militancias armadas: siguen siendo simplificadas desde el abordaje mediático, que siempre corre varios metros atrás que el arte o los estudios académicos.

\section{Conclusiones.}

Los casos trabajados, que brevemente hemos analizado en este artículo, representan solo una parte de un corpus de relatos que refieren al pasado reciente en los cuales observamos tanto la necesidad de visibilizar aspectos antes ocultos o negados como también transformar un trauma social y/o personal en una forma narrativa artística.

De los casos argentinos, tomamos una propuesta peculiar, tanto por su finalidad divulgadora de una búsqueda colectiva como también porque presenta una superación del constructo sobre "los dos demonios" que caracterizara a los discursos hegemónicos de la primera posdictadura en la década del ochenta. Historietas por la Identidad señala, entonces, un proceso discursivo que comienza a fortalecerse a partir de 2004 , con la inclusión en la agenda política- estatal de las demandas por la desaparición de personas. Como parte de este fenómeno, hemos referido brevemente al caso de revista Fierro, cuya política editorial incluyó a algunas de estas historietas en sus páginas.

Existe una tradición rioplatense en las historietas posdictatoriales que refieren sobre los crímenes de la dictadura, que busca reconstruir el pasado a partir de los relatos "no oficiales" u oscurecidos por el relato hegemónico. Este posicionamiento sobre el pasado, heredado en parte de algunas historietas de Oesterheld (Fernández, 2015), se observa tanto en el caso argentino como el uruguayo que trabajamos aquí.

El primero, a partir del intento de contar la vida personal de los militantes, sus costumbres, incluso sus gustos y características físicas con el fin de darle visibilidad a una búsqueda negada o minimizada durante años. Cabe destacar, a este respecto, que en la década del noventa, se intentó 
una falsa "conciliación social" apelando a desactivar estos reclamos que, no obstante, lograron mantenerse vigentes.

En el segundo caso, desde ese rescate de testimonios, anécdotas, de fragmentos de memorias para articularlos en una historia de ficción, basada en hechos reales pero concebida como un relato autónomo. Como señalamos, también existe un interés en salir del "lugar común", mediante la propuesta de matices en los personajes. Efectivamente hay antagonistas definidos, pero también existen matices en estas construcciones, que nos presentan un panorama más complejo de definir tradicionalmente entre "buenos" y "malos". El único personaje que cumple los requisitos de un "héroe" incuestionable, es el embajador de México, que expone su propia integridad física a fines de rescatar a un tupamaro que busca asilo.

Observamos que estos relatos apelan a enriquecer la "memoria colectiva" (Ricoeur, 1999), entendiendo que la construcción del recuerdo o de la memoria sobre el pasado no es una tarea solitaria, sino una apropiación y resignificación de elementos de relatos ajenos. Esta noción de construcción de un relato desde el fragmento, desde lo brumoso del recuerdo, es evidente en la historieta de Santullo y Bergara, pero también en la mayoría de las obras que componen Historietas por la Identidad.

Además, estas historietas tienen en común ese origen traumático, doloroso, al que tanto Ricoeur (1999) como La Capra (2005) refieren. Es pertinente definir estos trabajos como discursos de una "memoria herida" y también como "escrituras traumáticas o postraumáticas" (La Capra, 2005: 47), pues son respuestas a una circunstancia social violenta, que ha dejado una huella, un trauma, en esas comunidades. Herida a la cual intentan subsanar pero que, a la vez, también es un elemento común que funda identidades colectivas.

La rememoración del trauma permite nuevas lecturas, significados, reconocimientos e, incluso, nuevos "olvidos" en la memoria colectiva. La operación del retorno sobre el pasado traumático en estas historietas se alimenta tanto del acontecimiento al que alude o (re)visita como también de quien lo reconoce desde el presente (sea un individuo o un grupo social, una institución). Ese reconocimiento tiene que ver con las formas de identificación, las creencias puestas en valor por el juego hegemónico del momento. Implica una construcción del pasado que supone la revisión de las identidades en el presente.

Como cierre a estas conclusiones, siempre parciales, quisiéramos apuntar a una inquietud sobre el legado de estas operaciones estéticas y políticas analizadas en el campo cultural e intelectual latinoamericano.

El por qué de esta preocupación tiene una razón de actualidad candente. Este artículo comenzó a escribirse en un contexto gubernamental donde las "políticas de la memoria" y los avances en DD. HH. parecían verdades instaladas, conquistas que habían llegado para quedarse. El discurso 
del proyecto Historietas por la Identidad que hemos analizado aquí, pertenecen/ pertenecían a esa creencia que la sociedad argentina ha visto quebrarse entre los meses de diciembre de 2015 y abril de 2016, momento en el cual finalizamos este escrito.

Por un lado, porque existe una evidente avanzada de los discursos pro-militaristas, bajo los lemas de la seguridad nacional y un ferviente deseo reaccionario que avasalla espacios y publicaciones culturales que crecieron bajo el impulso a las producciones de arte popular como la historieta. Para citar solo dos casos, proyectos como el suplemento de historietas de la agencia Télam y las capacitaciones en historieta que ofrecía el entonces llamado Ministerio de Planificación, fueron cancelados con la administración de Mauricio Macri. Otros eventos de gran importancia local, como Comicópolis, amenazan con ser privatizados (y perder así su gratuidad y la apertura a todo público) o bien, desmantelados lentamente como es el caso de varios proyectos culturales similares.

Por otra parte, respecto del escenario uruguayo, los ya mencionados Fondos Concursables han reducido, desde el presente año, la cantidad de premios destinados a la categoría "relato gráfico". Esto inquieta a la pequeña industria local, que supo crecer en la última década gracias al impulso económico dado mediante dichos Fondos.

En este esquema, los discursos en historieta sobre la memoria reciente sufren un revés en sus espacios de influencia, en su capacidad de difusión y en sus posibilidades de existencia. Por supuesto, el mundo digital, (los revividos blogs, las páginas de historietas colectivas, entre otros) mantienen un lugar de subsistencia para estas obras, en la medida que la precarización laboral y la posibilidad del tiempo dedicado a la propia obra permita crear a sus autores en el imparable mundo neoliberal.

\section{6.. Bibliografía}

BOURDIEU, P. (1995). Las Reglas del Arte: Génesis y estructura del campo literario. Barcelona: Anagrama.

FERNÁNDEZ, L. (2015). Oesterheld como mito popular: el autor y su obra, desde la historieta como herramienta de cambio social hasta la transformación en símbolo político (1968-2010). [inédito] Tesis de Doctorado en Ciencias Sociales, Universidad Nacional de Cuyo, Mendoza, Argentina.

-- (2012). La Resistencia. Arte y política en Oesterheld (1968-1978). Mendoza: EDIUNC.

HISTORIETAS POR LA IDENTIDAD. (2012-2015). Recuperado de: http://hisxi.blogspot.com.ar/. Consultado el 30 de Noviembre de 2015. 
HISTORIETAS X LA IDENTIDAD (2014). Catálogo de la muestra. Buenos Aires: Abuelas de Plaza de Mayo - Biblioteca Nacional de la República Argentina.

LA CAPRA, D. (2005). Escribir la historia, escribir el trauma. Buenos Aires: Nueva Visión.

LONGONI, A. (2007). Traiciones. La figura del traidor en los relatos acerca de los sobrevivientes de la represión. Buenos Aires: Norma.

LONGONI, A. y M. Mestman (2010). Del Di Tella a "Tucumán arde". Vanguardia artística y política en el 68 argentino. Buenos Aires: Eudeba.

REGGIANI, F. (13-08-2010). "Historieta y memoria". Recuperado de: http://criptahda.matiasf.com.ar/2010/08/historieta-y-memoria/\#more-7037. Consultado el $\underline{30 \text { de Junio de } 2015 .}$

REVISTA FIERRO. La historieta Argentina (2006- 2015) ( $N^{\circ} 01$ - 100) Página 12: Buenos Aires.

RICHARD, N. (2007). Fracturas de la memoria. Arte y pensamiento crítico. Buenos Aires: Siglo XXI.

RICOEUR, P. (1999). La lectura del tiempo pasado: memoria y olvido. Madrid: Arrecife.

SANTULLO, R. y M. Bergara (2010). Acto de Guerra. Estuario: Uruguay.

SCHMUCLER, H. (2006). "La inquietante relación entre lugares y memorias". Uso público de los sitios históricos para la transmisión de la memoria. Espacio Memoria Abierta. Recuperado de:

http://www.memoriaabierta.org.ar/materiales/pdf/hector schmucler.pdf. Consultado el 2 marzo de 2012.

VAZQUEZ, L. (2010). El Oficio de las Viñetas: la industria de la historieta argentina. Buenos Aires: Paidós.

VEZZETTI, H. (2007). "Conflictos de la memoria en la Argentina. Un estudio histórico de la memoria social". Historizar el pasado vivo en América Latina. Recuperado de: http://etica.uahurtado.cl/historizarelpasadovivo/es contenido.php. Consultado el 12 de marzo de 2014.

-- (2013). Sobre la violencia revolucionaria. Memorias y olvidos. Buenos Aires: Siglo XXI. 


\section{(c) (1) ()}

Licencia Creative Commons

Miguel Hernández Communication Journal mhcj.es

\section{Forma de citar este artículo en las bibliografías}

Laura Cristina Fernández (2016): "La historieta como relato de un trauma social en América Latina: los casos Historietas por la Identidad (Argentina) y Acto de Guerra (Uruguay)", en Miguel Hernández Communication Journal, nº7, páginas 191 a 215. Universidad Miguel Hernández, UMH (Elche-Alicante). Recuperado el_ de___ de 20_ de: link del artículo en mhjournal.org] 